\title{
Sensitivity analysis for shear strength of flat interface between shotcrete and granite in high temperature tunnel
}

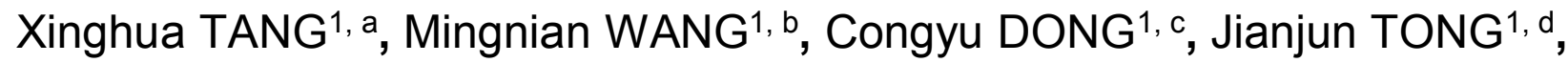 \\ Yicheng WANG ${ }^{1,}$, \\ ${ }^{1}$ Key Laboratory of Transportation Tunnel Engineering, Ministry of Education, School of Civil \\ Engineering, Southwest Jiaotong University, Chengdu Sichuan 610031,China \\ a10521801@qq.com, b19910622@163.coml, c362698067@qq.com, d414417808@qq.com, e \\ 236636213@qq.com
}

\begin{abstract}
Keywords: tunnel; high rock temperature; shotcrete; shear strength; sensitivity.
Abstract: For the sensitivity on the shear strength of flat interface between shotcrete and granite in high temperature tunnel, shear experiments were performed with concrete-granite combined specimens. By calculating the sensitivities of temperature, relative humidity, normal stress and concrete strength, the sensitivities of peak shear strength and residual shear strength were evaluated. The results show that the most sensitive factor is temperature and the more sensitive factors are relative humidity and normal stress for peak shear strength. Whereas it has weak correlation with concrete strength. The most sensitive factor is normal stress for residual shear strength, and all of temperature, relative humidity and concrete strength are weakly relative to it. High rock temperature has great influence on the peak shear strength, however, little effect on the residual shear strength which is similar to normal temperature.
\end{abstract}

\section{Introduction}

When tunnel is affected by excessive cover depth or geothermal water including magmation and thermal spring, the temperature will exceed $28{ }^{\circ} \mathrm{C}$ during tunnel construction process, also the construction safety and staff health are affected ${ }^{[1]-[2]}$. These are called high-temperature tunnels.

Currently many high-temperature tunnels have been built in the world ${ }^{[3]-[5]}$, also many construction technology problems, which including cooling by ventilation, construction blasting, geothermal water processing and personal protection, have been initially solved. However, many fundamentally mechanical problems have not been studied. The bond and shear properties between shotcrete and rock is one of the typical examples.

Tab. 1 Main high temperature tunnels successfully built in the world

\begin{tabular}{|c|c|c|c|c|c|}
\hline Nation & Tunnel Name & Length $/ \mathrm{km}$ & $\begin{array}{l}\text { Maximum } \\
\text { cover } \\
\text { depth } / \mathrm{m}\end{array}$ & $\begin{array}{l}\text { Maximum } \\
\text { temperature } /{ }^{\circ} \mathrm{C}\end{array}$ & Main lithology \\
\hline China & $\begin{array}{l}\text { Qirehataer hydropower station } \\
\text { diversion tunnel }\end{array}$ & 15.639 & 1720 & 98 & granitic gneiss \\
\hline Japan & Abo Main tunnel & 4.35 & 700 & 75 & granite porphyry \\
\hline China & Jiwoxiga tunnel & 3.985 & 102 & 65.4 & diorite \\
\hline Italy & Apennine railway tunnel & 18.518 & 2000 & 63.8 & sandy gneiss \\
\hline Switzerland & Simplon tunnel & 19.8 & 2140 & 55.4 & granite、 gneiss \\
\hline China & Jiuzai tunnel & 4.46 & 150 & 52 & clastic rocks \\
\hline America & Tecolote tunnel & 6.4 & 2287 & 47 & $\begin{array}{l}\text { sandstone } \\
\text { siltstone }\end{array}$ \\
\hline Switzerland & New Sait Gotthard tunnel & 57 & 2300 & 45 & gneiss 、 dolomite \\
\hline
\end{tabular}

The bond and shear problems between concrete and rocks in normal temperature have been fully studied in the world, but research under high-temperature are insufficient. 
Liu Jian(2000) ${ }^{[6]}$ carried out splitting tensile tests about new and old concrete bond samples under $200^{\circ} \mathrm{C}$. Guo Jinjun $(2003){ }^{[7]}$ developed splitting tensile tests and shear tests under the condition of fire disaster $\left(200{ }^{\circ} \mathrm{C} \sim 900{ }^{\circ} \mathrm{C}\right)$. Ou Zaohua(2011) ${ }^{[8]}$ studied the bonding tensile strength for interface between shotcrete and rocks in high temperature via splitting tensile test. Cui Sheng'ai(2013) ${ }^{[9]}$ measured the bonding strength for interface between shotcrete and rocks in high geothermal tunnel by adopting improved core drawing method. The research mentioned above mainly focused on the bonding problem between concrete and rock. As for shear problem, the high-temperature effect were taken into account, and the fire imposed on the concrete after hardening and congealing, which cannot match the practical situation in high-temperature tunnel. Therefore, research on shear properties and sensitivity analysis of effective factors are full of theoretical value and engineering significance.

\section{Shear Test}

\section{Sample preparation}

Combined specimen of shotcrete and granite is adopted in the tests with the size of $10 \mathrm{~cm} \times 10 \mathrm{~cm} \times$ $10 \mathrm{~cm}$, which is consisted of $50 \%$ concrete and $50 \%$ granite, shown in Fig.1. The steps of sample preparation are as follow. (1) preparing granite samples; (2) putting granite into the mold and pouring concrete; (3) conducting high-temperature maintenance of combined specimen; (4) trimming and polishing the combined specimen to be a standard cube.

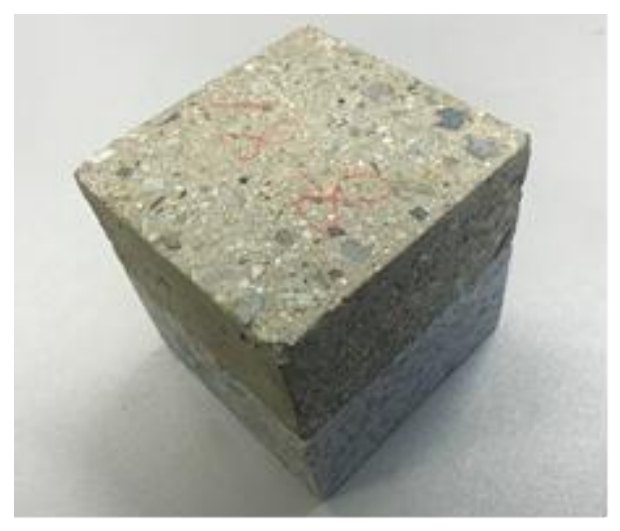

Fig. 1 Combined specimen

Granite

After trimming and polishing, the size of granite is $10 \mathrm{~cm} \times 10 \mathrm{~cm} \times 5 \mathrm{~cm}$. As for granite sample, the bottom and side surfaces are smooth, while the upper surface (interface between concrete and granite) is flat.

According Barton's typical JRC model, the value of roughness for upper surface is $0 \sim 2$. The physical and mechanical parameters for granite are gained by laboratory tests, shown in Tab.2.

Tab. 2 Physical and mechanical parameters for granite

\begin{tabular}{cccccc}
\hline $\begin{array}{c}\text { Density } \\
\rho /(\mathrm{kg} / \mathrm{m} 3)\end{array}$ & $\begin{array}{c}\text { Elasticity } \\
\text { modulus } \\
\mathrm{E} /(\mathrm{GPa})\end{array}$ & $\begin{array}{c}\text { Poisson's } \\
\text { ratio } \\
\lambda\end{array}$ & $\begin{array}{c}\text { Cohesion } \\
\mathrm{c} /(\mathrm{MPa})\end{array}$ & $\begin{array}{c}\text { Frictional } \\
\text { angle } \\
\varphi /{ }^{\circ}\end{array}$ & $\begin{array}{c}\text { Uniaxial compressive } \\
\text { strength } \\
\mathrm{R} /(\mathrm{MPa})\end{array}$ \\
\hline $2.59 \times 103$ & 35.75 & 0.28 & 3.63 & 20.3 & 61.83 \\
\hline
\end{tabular}

Shotcrete

The design strength of shotcrete is $\mathrm{C} 25$ or $\mathrm{C} 30$, with the normal mix proportions for shotcrete in tunnel, shown in Tab.3. 
Tab. 3 Mix proportions for concrete

\begin{tabular}{lllllllll}
\hline $\begin{array}{l}\text { Design } \\
\text { strength }\end{array}$ & $\begin{array}{l}\text { Water } \\
\text { cement } \\
\text { ratio }\end{array}$ & $\begin{array}{l}\text { Sand } \\
\text { ratio }\end{array}$ & $\begin{array}{c}\text { Cement } \\
(\mathrm{kg} / \mathrm{m} 3)\end{array}$ & $\begin{array}{c}\text { Water } \\
(\mathrm{kg} / \mathrm{m} 3)\end{array}$ & $\begin{array}{c}\text { Sand } \\
(\mathrm{kg} / \mathrm{m} 3)\end{array}$ & $\begin{array}{c}\text { Gravel } \\
(\mathrm{kg} / \mathrm{m} 3)\end{array}$ & $\begin{array}{l}\text { Accelerator } \\
\text { amount }\end{array}$ & $\begin{array}{l}\text { Water } \\
\text { reducing } \\
\text { agent }\end{array}$ \\
\hline C25 & 0.49 & $50 \%$ & 436.53 & 213.9 & 949.79 & 949.79 & $4 \%$ & $1 \%$ \\
C30 & 0.45 & $49 \%$ & 442 & 200 & 949 & 987 & $4 \%$ & $1 \%$ \\
\hline
\end{tabular}

Where, Cement mark is P.O42.5; sand is medium, fineness modulus is 2.54; gravel particle size is 5 10mm.

The samples are poured according to the design proportion, and placed under indoor temperature. After the initial congealing, the samples and modulus are conducted maintenance by putting into a constant-temperature and constant-moisture test box. Maintenance moisture is constant, while the maintenance temperature is gradually reduced to $28{ }^{\circ} \mathrm{C}$ from initial temperature (for example: $40^{\circ} \mathrm{C}, 60^{\circ} \mathrm{C}, 80^{\circ} \mathrm{C}, 100^{\circ} \mathrm{C}$ ) during the first five days, and keeps $28^{\circ} \mathrm{C}$ from the 6 th to 28 th day. The main aim of adopting this maintenance method is to simulate the evolution process for temperature filed in the construction process of high-temperature tunnel, and to make sure that the indoor maintenance condition conforms to practical engineering.

Loading device and method

YDS-2 type multi-function rock testing machine was adopted. Normal stress was applied by vertical oil cylinder at first, and then horizontal stress was applied by horizontal oil cylinder when normal stress became steady. The loading process was called shear test. Test data collection was controlled by instrumental sensor system, which including two stress sensors (one normal stress sensor and one shear sensor) and six displacement sensors (four normal displacement sensors and two horizontal displacement sensors).

Test grouping

The number of group was determined by, which takes into account of temperature, relative moisture, normal stress and concrete strength. The value of each effective factor was determined according to the practical situation in high-temperature tunnel, shown in Tab.4.

Tab. 4 Effective factors and values

\begin{tabular}{cc}
\hline Effective factors & Values \\
\hline Temperature $\left(\mathrm{T} /{ }^{\circ} \mathrm{C}\right)$ & $40 、 60 、 80 、 100$ \\
relative moisture $(\varphi / \%)$ & $55 、 95$ \\
normal stress $(\sigma / \mathrm{MPa})$ & $0.5 、 1.0 、 1.5$ \\
concrete strength $(\mathrm{f})$ & $\mathrm{C} 25 、 \mathrm{C} 30$ \\
\hline
\end{tabular}

144 samples were included within 48 groups which contain 3 samples. Moreover, one standard maintenance test (Maintenance temperature is $20{ }^{\circ} \mathrm{C}$ and relative moisture is $95 \%$ ) was added as comparison.

\section{sensitivity analysis method}

Sensitivity analysis was important in system analysis. three steps were included as follows ${ }^{[10]-[11]}$.

(1) Function between system model and factors was established as follows.

$$
Y=f\left(X_{1}, X_{2} \cdots \cdots X_{n}\right)
$$

Where $\mathrm{Y}$ is systematically characteristic value; $\mathrm{Xn}$ is the nth effective factor.

Analysis of each factor should be conducted individually. Y value is sensitive to the factor if the variation of $\mathrm{Y}$ value, which was individually caused by $\mathrm{Xi}$, is bigger.

(2) Definition of systematic parameters set. A reference object was defined, and systematic analysis should be conducted combined with specific test objective. Also the sensitivity of the factor should be considered. The reference value should be constant and obtained according to the specific problem. 
(3) Analysis and calculation of sensitivity:

Computational formulas of sensitivity for every factor were as follows:

$$
\begin{aligned}
& S_{\mathrm{i}}=\frac{\eta_{1}}{\eta_{2}} \\
& \eta_{1}=\frac{\left|\Delta Y_{\mathrm{j}}\right|}{Y_{\mathrm{j} 0}} \\
& \eta_{2}=\frac{\left|\Delta X_{\mathrm{i}}\right|}{X_{i, \max }-X_{i, \text { min }}}
\end{aligned}
$$

Where: $\eta_{1} \longrightarrow$ variation rate of characteristic value $Y_{\mathrm{j}}$ vs $\mathrm{Xi} ; \eta_{2} \longrightarrow$ variation rate of the factor $\mathrm{Xi} ; \Delta \mathrm{Xi}-$ variation of the factor $\mathrm{Xi}$, and $\Delta X_{\mathrm{i}}=X_{\mathrm{i}}-X_{\mathrm{i}}^{*}, X_{\mathrm{i}}^{*}$ - reference value of the factor Xi; $X_{i, \max }, X_{i, \min } \longrightarrow$ the maximum and minimum value of the factor $\mathrm{Xi} ; Y_{\mathrm{j} 0} \longrightarrow$ systematically characteristic value under the condition of every factor; $\Delta Y_{\mathrm{j}}$ —variation of the systematically characteristic value.

\section{Sensitivity analysis of shear strength}

Shear strength should be matched with formula 1, and temperature, relative moisture, normal stress and concrete strength should be considered.

$$
\tau=\mathrm{f}(T, \varphi, \sigma, f)
$$

The reference values of the four factors can be selected in line with Tab.5.

Tab. 5 Reference for base values of all the factors

\begin{tabular}{cccccc}
\hline $\begin{array}{c}\text { Temperature } \\
\left(\mathrm{T} /{ }^{\circ} \mathrm{C}\right)\end{array}$ & $\begin{array}{c}\text { Relative } \\
\text { humidity }(\varphi / \%)\end{array}$ & $\begin{array}{c}\text { Normal stress } \\
(\sigma / \mathrm{MPa})\end{array}$ & $\begin{array}{c}\text { Concrete } \\
\text { strength }(\mathrm{f})\end{array}$ & $\begin{array}{c}\text { Peak shear } \\
\text { strength }(\tau \mathrm{u} / \mathrm{MPa})\end{array}$ & $\begin{array}{c}\text { Residual shear } \\
\text { strength }(\tau \mathrm{u} / \mathrm{MPa})\end{array}$ \\
\hline 40 & 95 & 0.5 & $\mathrm{C} 30$ & 2.309 & 0.544 \\
\hline
\end{tabular}

Sensitivities for the peak of shear strength and residual shear strength vs temperature (relative moisture, normal stress and concrete strength) are calculated according to formulas 2,3 and 4 , shown in Tab.6.

Tab. 6 Sensitivities of shear strengths

\begin{tabular}{cccc}
\hline Factors & & Peak shear strength $\left(\tau_{\mathrm{u}} / \mathrm{MPa}\right)$ & Residual shear strength $\left(\tau_{\mathrm{u}} / \mathrm{MPa}\right)$ \\
\hline & 20 & 1.887 & 0.09 \\
& 60 & 1.938 & 0.297 \\
Temperature $\left(\mathrm{T} /{ }^{\circ} \mathrm{C}\right)$ & 80 & 1.3815 & 0.12 \\
& 100 & 0.408 & 0.074 \\
& & $1.404^{*}$ & $0.145^{*}$ \\
\hline Relative moisture $(\varphi / \%)$ & 55 & 0.567 & 0.014 \\
\hline & 1 & 0.828 & 1.232 \\
Normal stress $(\sigma / \mathrm{MPa})$ & 1.5 & 0.948 & 0.682 \\
& & $0.888^{*}$ & $0.957^{*}$ \\
\hline Concrete strength $(\mathrm{f})$ & $\mathrm{C} 25$ & 0.121 & 0.04 \\
\hline
\end{tabular}

Where, the sign $(*)$ means average.

Sensitivities of shear strengths (shown in Fig.2) can be drawn according to Tab.6. 


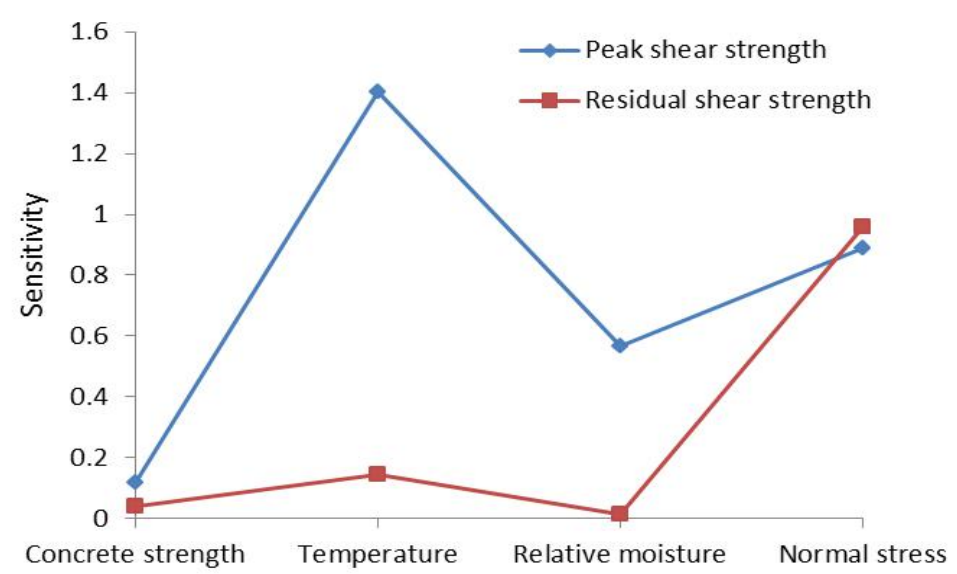

Fig. 2 Sensitivities of shear strengths

According to Fig.2, the most sensitive factor of shear strength is temperature, and the second sensitive factors of shear strength are stress and moisture, but for concrete strength, the sensitivity is very low.

The shear strengths of concrete and rock interface reduce under the action of high temperature. The velocity of hydration for binding materials accelerates under the influence of high temperature during the congealing and hardening process of shotcrete. The hydration productions cannot diffuse homogeneously and the overlap degenerated, which can result in the looseness of concrete microstructure and the insufficient development of concrete strength and rock binding strength. The temperature is the most sensitive factor to the reduction of peak shear strength.

On the other hand, the sensitivity of peak shear strength with respect to concrete strength is very low. The concrete strength reduces under high temperature, and the difference between C25 and C30 decrease, which lead to the reduction of sensitivity for peak shear strength with respect to concrete strength.

The most sensitive factor of residual shear strength is normal stress, but with respect to temperature, relative moisture and concrete strength, its sensitivity is low. Friction action is the only source of residual shear strength after the fracture of concrete and granite interface, and then the normal stress is the main control factor. As for temperature and relative moisture, the influence to residual shear strength is low although the binding strength, which is meaningless to shear strength after the fracture, can be reduced by them.

\section{Conclusion}

Sensitivity analyses of shear strength with respect to effective factors for shotcrete and granite flat interface were conducted via laboratory shear tests, and conclusion can be obtained as follows.

(1) As for peak shear strength, the temperature is the most sensitive factor, and the normal stress and moisture are the second sensitive ones, while the sensitivity to concrete strength is low. The result indicates that high temperature have an important influence on shear strength of interface between shotcrete and rock.

(2) As for residual shear strength, the most sensitive factor is normal stress, while its sensitivities to temperature, relative moisture and concrete strength are low. The result indicates that the residual shear strength between shotcrete and rock in high temperature tunnel is the same with that in normal temperature tunnel.

\section{References}

[1] Ministry of Railways Economic Planning Research Institute: Guide (TZ204-2008), China Railway Publishing House. (In Chinese) 
[2] Ministry of Transport of the People's Republic of China: Specification (JTG F60-2009), China Communication Press. (In Chinese)

[3] R.Q. Huang, X.N. Wang: Journal of Geological Hazards and Environment Preservation Vol. 8 (1997), p. 50-68. (In Chinese)

[4] C.S. Yang: Railway Construction Technology Vol. 10 (2010), p. 39-46. (In Chinese)

[5] J. Liu: Railway Construction Technology Vol.2 (2010), p. 19-22. (In Chinese)

[6] J. Liu: Master's thesis (2000), Dalian University of Technology. (In Chinese)

[7] J.J. Guo: Master's thesis (2003), Dalian University of Technology. (In Chinese)

[8] Z.H. Ou: Master's thesis (2011), Southwest Jiaotong University. (In Chinese)

[9] S.A. Cui, J.W. Li, Y.Z. Ye and H.Y. Yang: Journal of building materials Vol. 4 (2013), p. $663-666+682$.

[10] G. Zhang and W.S. Zhu: Rock and Soil Mechanics Vol. 14 (1993), p. 51-58. (In Chinese)

[11] K.Z. Song, F.X. Li, L.M. Zhu and M.S. Wang: Journal of highway and transportation research and development Vol. 31 (2014), p. 86-91. (In Chinese) 